\title{
A Prognostic Method for Scheduling Maintenance on the P2- Marx Modulator
}

\author{
Andrew Benwell, Craig Burkhart, Mark Kemp, Koen Macken, Minh Nguyen, Dave MacNair, Jeff Olsen, Ray Larsen \\ Power Conversion Department \\ SLAC National Accelerator Laboratory \\ Menlo Park, CA 94025
}

\begin{abstract}
The SLAC National Accelerator Laboratory is developing a second generation Marx-type modulator for the ILC, the P2-Marx. The modulator is expected to operate reliably in excess of $10^{5}$ hours with minimum downtime. A prognostic system is being implemented with the development of the P2Marx to monitor and track the health of key high voltage components. This paper discusses the way in which the prognostic system will be implemented and used to monitor the health of the P2-Marx modulator.
\end{abstract}

Keywords-prognostics; power electronics; high voltage

\section{INTRODUCTION}

The SLAC National Accelerator Laboratory is developing a second generation Marx-type modulator for the ILC, the P2 Marx [1]. The P2 Marx modulator will produce $120 \mathrm{kV}, 1.6$ microsecond pulses by summing the output voltage from 32 self-regulating Power Electronic Building Blocks (PEBBs), referred to as cells in this paper. Each cell will contain the necessary hardware to provide droop compensated $4 \mathrm{kV}, 140$ A pulses.

The P2 Marx will be modular; allowing for easy maintenance or replacement of its individual cells. When a particular cell is exhibiting reduced performance, it can be simply replaced by a new cell in the modulator so that refurbishment can be carried out. Fig. 1(a) depicts the 32 cell modulator as it is approached by an average height person preparing to remove one cell. The single cells, represented by the rectangle boxes, are arranged as shown by Fig. 1(b) so that they are charged in parallel and discharged in series.

To determine when one particular cell needs replacement, the P2 Marx design provides adequate diagnostic access for discerning and repairing modulator faults with minimal intrusion. In addition to diagnosing faults, a prognostic approach will be used to monitor the health of several key cell components and to predict their end of life while they are in their actual working environment. By using a prognostic method to track the health of each individual cell, the maintenance of the modulator can be simplified and its availability maximized.

Of chief concern is the condition of the charge and discharge IGBTs for both the main and regulation portion of the cell circuit as well as the condition of the main and regulation energy storage capacitors. IGBT health will be observed by recording significant changes in the collector-

Work supported by the US Department of Energy under contract DEAC0276SF00515. Email: abenwell@slac.stanford.edu emitter on-state voltage, $\mathrm{V}_{\mathrm{CE}(\mathrm{SAT})}$ [2]. Storage capacitor aging can be tracked by recording changes in capacitance, measured in situ from capacitor voltage and charge current [3].

Under normal operation, the P2 Marx will provide pulses at $5 \mathrm{~Hz}$. This repetitive operation aids in distinguishing small changes in measured values because large data sets can be collected for each measurement. With an appropriate prognostic algorithm, the remaining lifetime of a component can be calculated and a warning can be issued if necessary [4]. This paper details the prognostic scheme developed to monitor the health of the P2 Marx.

\section{PROGNOSTICS OF HIGH VOLTAGE COMPONENTS}

\section{A. IGBT health}

Solid-state high voltage switching encompasses one of the two focus points for prognostic evaluation of the P2-Marx. High voltage IGBTs are used in both the charge and discharge cycles of the main and regulation cells. Four IGBTs per cell, 128 IGBTs total, will be monitored by the prognostic system for reduced performance.

A physics of failure approach will be used to predict the end of life of the IGBTs. For this approach, the failure mechanism of the device is predicted to occur in a way that has been observed experimentally [5]. Appropriate diagnostics are implemented to observe that failure. Thermal cycling is the most common cause of power electronics device failure. An IGBT that has undergone extensive thermal cycling frequently exhibits a change in the collector-emitter voltage during normal conduction [6]. A mismatch of thermal expansion coefficients leads to internal stresses within the IGBT modules. Over time the internal stresses lead to fractures near the connection points of mismatched materials. This typically results in solder joint failure or wirebond liftoff which will affect the electrical characteristics of the IGBT [7]. A variation in the collector emitter voltage of $15 \%$ is an indication that the IGBT is approaching its end of life [8].

To monitor the health of the IGBTs used in the P2-Marx, the collector-emitter voltage will be measured for signs of change. The main and regulation IGBTs, which block up to 4 $\mathrm{kV}$ and $1 \mathrm{kV}$ respectively, are expected to operate at $55{ }^{\circ} \mathrm{C}$. The charge and discharge IGBTs of the cell main circuit are $6.5 \mathrm{kV}$ IGBT modules located at (d) and (e) in the 


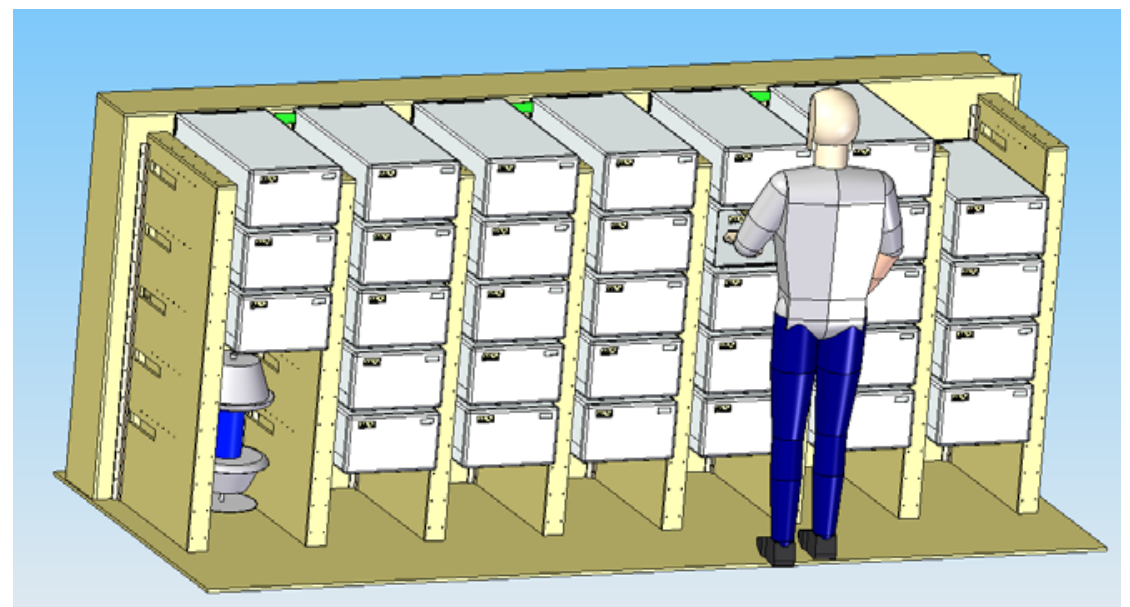

(a)

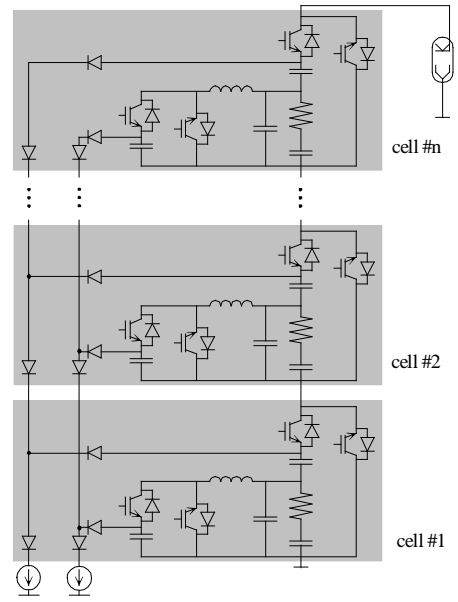

(b)

Fig. 1: An arrangement of the 32 Cell P2-Marx (a) with a representative circuit (b). Each $4 \mathrm{kV}$ rectangular cell can be removed and replaced from its slot, or bypassed through the cells main charging IGBT shown in (b) to minimize modulator downtime. High voltage bus bars (green) and an output voltage monitor (blue) are visible.

simplified cell schematic, Fig. 2. With $15 \mathrm{~V}$ applied to the gate, $\mathrm{V}_{\mathrm{CE}(\mathrm{SAT})}=4.6 \mathrm{~V}$ at $55^{\circ} \mathrm{C}$. A deviation of $\pm 690 \mathrm{mV}(15$ $\%)$ from $4.6 \mathrm{~V}$ indicates significant damage has occurred to the IGBT and the prognostic system should schedule a maintenance procedure.

Similarly the charge and discharge IGBTs of the cell regulation circuit are $1.7 \mathrm{kV}$ IGBT modules located at (a) and (b) in the simplified cell schematic, Fig. 2. With $15 \mathrm{~V}$ applied to the gate, $\mathrm{V}_{\mathrm{CE}(\mathrm{SAT})}=2.12 \mathrm{~V}$ at $55{ }^{\circ} \mathrm{C}$. A deviation of \pm 318 $\mathrm{mV}(15 \%)$ from $2.12 \mathrm{~V}$ indicates significant damage has occurred to the IGBT and the prognostic system should schedule a maintenance procedure for the cell.

\section{B. Energy storage capacitor health}

The main and regulation energy storage capacitors are the second focus point for prognostic evaluation of the P2-Marx. Self-healing polypropylene film capacitors are used for energy storage and are shown in shown in Fig. 2 at (c) and (f). Two capacitors per cell, 64 capacitors total, will be monitored by the prognostic system for reduced performance.

The physics of failure for high voltage polymer-film capacitors is described thoroughly in [9]. As these capacitors age, an overall gradual reduction in capacitance is observed [10], and the total energy stored by the capacitor for a given voltage is reduced. A reduction in capacitance of $5 \%$ will indicate that the capacitor is approaching its end of life.

To monitor the health of the energy storage capacitors used in the P2-Marx the capacitor voltage and current will be recorded during the charge cycle of the modulator. From these signals the capacitance can be calculated by

$$
C_{\text {cap }}=\frac{i}{d v / d t} .
$$

The main energy storage capacitor is composed of four 87.5 $\mu \mathrm{F}$ capacitors for a total of $350 \mu \mathrm{F}$. The regulation capacitor is a single $850 \mu \mathrm{F}$ capacitor. For the prognostic system, the main energy storage capacitors will be lumped together for a single evaluation. If either the main or regulation capacitance drops to below $332 \mu \mathrm{F}$, or $808 \mu \mathrm{F}$ respectively, the prognostic system will schedule a maintenance procedure.

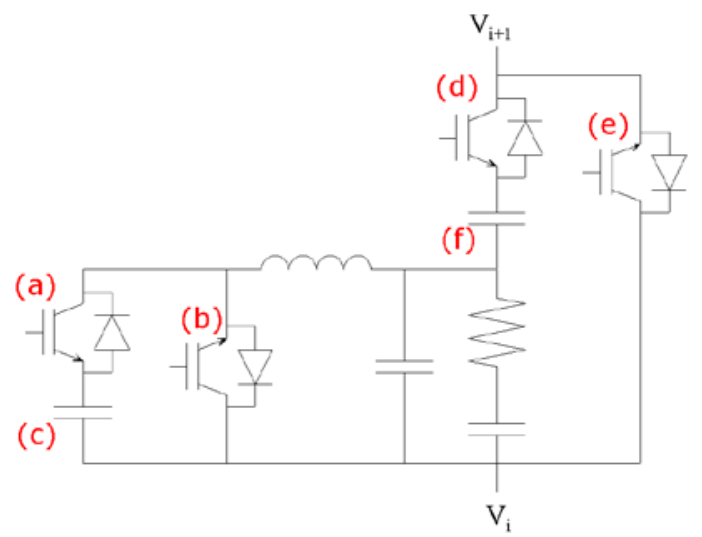

Fig. 2: A simplified schamtic of a single P2-Marx cell. (a) and (b) are discharge and charge IGBTs for the regulation circuit. (d) and (e) are the discharge and charge IGBTs for the main circuit. (c) and (f) are the energy storage capacitors for the regulation and main circuit respectively.

\section{PROgnostics InTERfaCe}

A hierarchal control architecture with three layers is used to integrate the P2-Marx PEBB design. This architecture for the P2-Marx was discussed in detail in [11]. It is composed of three layers: a system level controller, an application manager, and a hardware manager. The system level controller performs the highest level control such as responding to user commands and monitoring the entire system execution. The application manager (AM) handles intermediate level tasks specific to one modulator such as initialization, and diagnostics. The hardware manager (HM) controls the 
modulator at the PEBB level by handling fast and low level hardware related tasks such as signal sensing, PWM generation, and gate drive control. Fig. 3 outlines the roles of the control architecture and the communication between architecture layers.

By definition, the prognostic system is not intended for fast fault detection or for quick decision making. Instead it relies on long term data and creates notifications long before a real problem exists. Furthermore, given the expected long lifespan of the high voltage components, prognostic analysis is unlikely to be of interest to users on a regular basis. Under the described hierarchal architecture, the most logical place for prognostic decisions to take place is at the application manager layer.

To determine the health of a single Marx cell, the important cell prognostic signals are collected at the hardware manager either directly at the $\mathrm{A} / \mathrm{D}$ converter or from the gate driver. The digital information is then passed to the application manager via an Ethernet switch. The data will be buffered with some latency, which is acceptable due to the slow nature of prognostic decisions. The PC based application manager will record one value per IGBT, $\mathrm{V}_{\mathrm{CE}(\mathrm{SAT})}$, and five values per capacitor, $\mathrm{i}_{\text {charge }}, \mathrm{v}\left(\mathrm{t}_{1}\right), \mathrm{v}\left(\mathrm{t}_{2}\right), \mathrm{t}_{1}$, and $\mathrm{t}_{2}$. Capacitance will then be calculated.

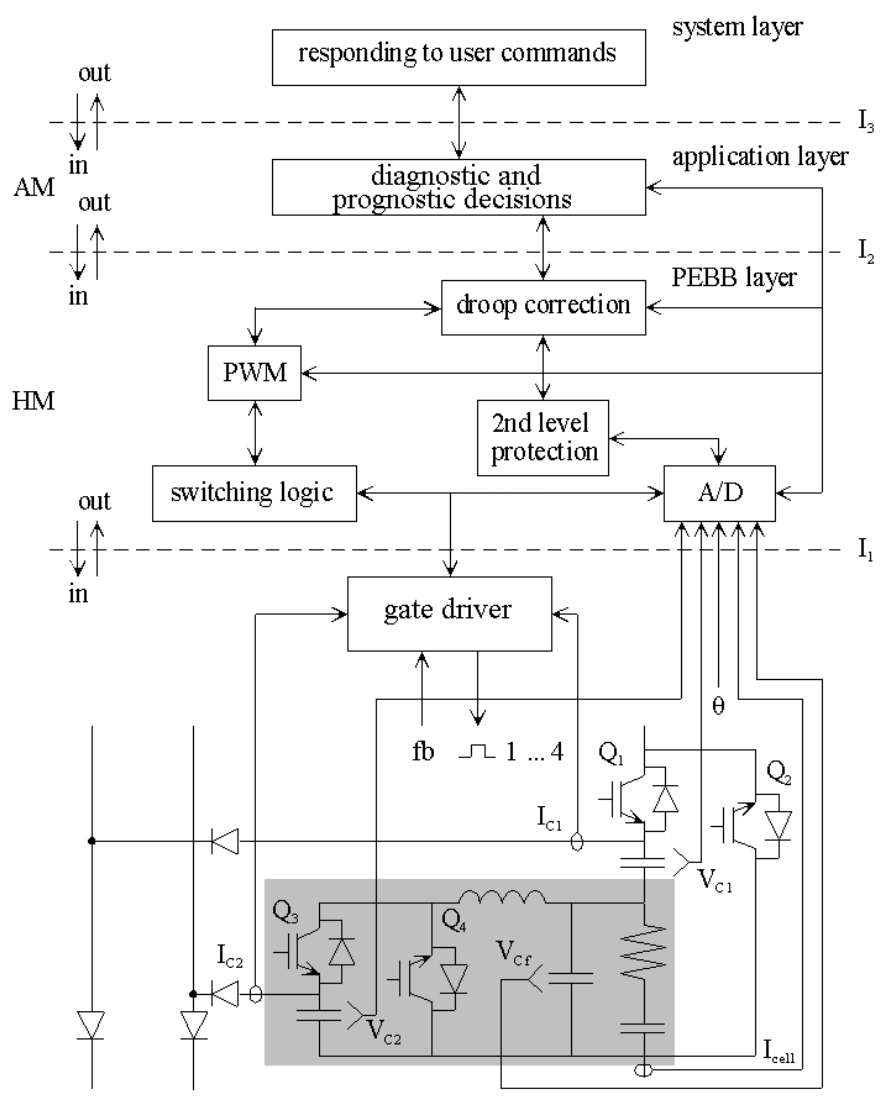

Fig. 3: Control architecture of the PEBB-based Marx modulator as it interfaces with a single cell. Cell signals are taken and processed by the hardware manager before being passed to the application manager for prognostic analysis.
Because of the repetitive nature of the Marx modulator operation, a large sample of data will be available for

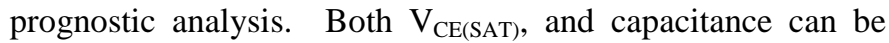
calculated at regular intervals and compared to a large pool of

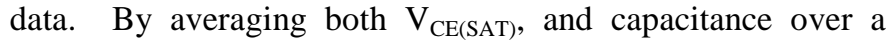
predetermined number of samples before calculating the remaining life of the component, noise in the measured data can be reduced. This will help to avoid false alarms and unneeded maintenance. In addition, a settling time will be implemented after the modulator is initially turned on to stabilize the measured signals. The outline of the prognostic system is shown in Fig. 4.

\section{SUMMARY}

A prognostic method has been developed for the P2-Marx modulator. When implemented, the system will monitor the health of the modulator power IGBT modules and energy storage capacitors by measuring $\mathrm{V}_{\mathrm{CE}(\mathrm{SAT})}$ and capacitance respectively. The system will then compare those values to expected component values.

The prognostic system will help to identify specific modulator cells that are in need of replacement or refurbishment. Because of the PEBB architecture of the P2Marx, the prognostic system is particularly useful for identifying the specific cell that is in need of maintenance. The system will be useful in simplifying modulator maintenance and minimizing downtime.

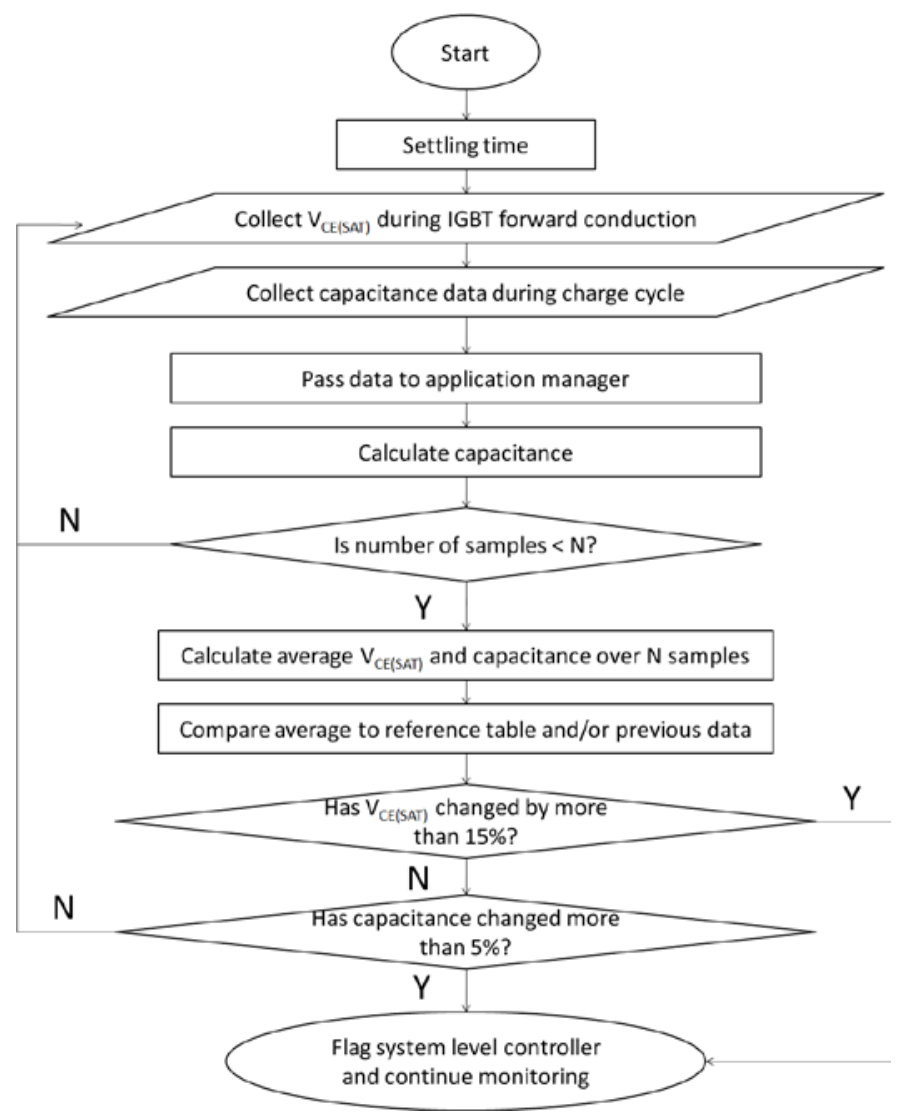

Fig. 4: A flowchart outlining the prognostic system 


\section{REFERENCES}

[1] C. Burkhart, T. Beukers, M. Kemp, R. Larsen, K. Macken, M. Nguyen, J. Olsen, and T. Tang, "Ilc marx modulator development program status," in Preceedings of the 2009 Particle Accelerator Conference, 2009.

[2] N. Patil, J. Celaya, D. Das, K. Goebel, and M. Pecht, "Precursor parameter identification for insulated gate bipolar transistor (igbt) prognostics," Reliability, IEEE Transactions on, vol. 58, pp. 271 -276, june 2009.

[3] J. Gu, M. H. Azarian, and M. G. Pecht, "Failure prognostics of multilayer ceramic capacitors in temperature-humidity-bias conditions," in Preceedings of the International Conference on Prognostics and Health Management, 2008.

[4] N. M. Vichare and M. Pecht, "Prognostic and health management of electronics," IEEE Transactions on Components and Packaging Technologies, vol. 29, pp. 222-229, 2006.

[5] C. Yin, H. Lu, M. Musallam, C. Bailey, and C. Johnson, "A prognostic assessment method for power electronics modules," in Electronics System-Integration Technology Conference, 2008. ESTC 2008. 2nd, pp. 1353 -1358, 1-4 2008.

[6] N. Patil, D. Das, C. Yin, H. Lu, C. Bailey, and M. Pecht, "A fusion approach to igbt power module prognostics," in Thermal, Mechanical and Multi-Physics simulation and Experiments in Microelectronics and Microsystems, 2009. EuroSimE 2009. 10th International Conference on, pp. 1 -5, 26-29 2009.

[7] C. Bailey, H. Lu, and T. Tilford, "Predicting the reliability of power electronic modules," in Electronic Packaging Technology, 2007. ICEPT 2007. 8th International Conference on, pp. 1 -5, 14-17 2007.

[8] Y. Xiong, X. Cheng, Z. Shen, C. Mi, H. Wu, and V. Garg, "Prognostic and warning system for power-electronic modules in electric, hybrid electric, and fuel-cell vehicles," Industrial Electronics, IEEE Transactions on, vol. 55, pp. 2268-2276, June 2008.

[9] C. Reed and S. Cichanowski, "The fundamentals of aging in hv polymer-film capacitors," Dielectrics and Electrical Insulation, IEEE Transactions on, vol. 1, pp. 904 -922, oct 1994.

[10] W. Sarjeant, F. MacDougall, D. Larson, and I. Kohlberg, "Energy storage capacitors: aging, and diagnostic approaches for life validation," Magnetics, IEEE Transactions on, vol. 33, pp. 501 -506, jan 1997.

[11] K. Macken, C. Burkhart, R. Larsen, M. Nguyen, and J. Olsen, "A hierarchical control architecture for a pebb-based ilc marx modulator," in Pulsed Power Conference, 2009. PPC '09. IEEE, pp. 826 -831, june 2009. 